\title{
"NUNCA SE ABANDONA A POESIA NEM NUM PARQUE, NEM NA VIDA", VAMOS COMPRAR UM POETA, DE AFONSO CRUZ
}

\author{
“NEVER LEAVE POETRY NEITHER IN A PARK, \\ OR IN LIFE", VAMOS COMPRAR UM POETA, \\ BY AFONSO CRUZ
}

Carlos Roberto dos Santos Menezes ${ }^{1}$

Publicado inicialmente em Portugal em 2016, chega às livrarias brasileiras o livro Vamos comprar um poeta, do autor português, Afonso Cruz, que tem sua estreia na editora Dublinense, através da Coleção Gira, cujo propósito inicia-se pela concepção de que

a língua portuguesa não é uma pátria, é um universo que guarda as mais variadas expressões. $\mathrm{E}$ foi para reunir esses modos de usar e criar através do português que surgiu a Coleção Gira, dedicada às escritas contemporâneas em nosso idioma em terras não brasileiras².

O conceito que estrutura e alinha as publicações pertencentes à Coleção Gira vão ao encontro do princípio de composição dos autores portugueses pertencentes à novíssima geração literária, a qual Afonso Cruz integra e cuja produção ficcional iniciou-se a partir dos anos 2000. O que se observa é a inclinação desses autores para um modo de pensar cosmopolita, cujos temas e problemas tratados em suas narrativas refletem os novos mo- 
delos éticos, políticos e culturais do mundo globalizado, de modo a incitar uma forma de reflexão a respeito das diversas mutações geradas no mundo contemporâneo. Neste sentido, tais obras buscam ultrapassar as fronteiras territoriais, culturais e nacionais com o intuito de focalizar as problemáticas do humano num contexto universal, mas que não exclui a presença de aspectos culturais, políticos, históricos da nação portuguesa ${ }^{3}$.

Entre os autores que integram a novíssima geração estão presentes, na coleção Gira, os portugueses Afonso Cruz, José Luís Peixoto, Gonçalo M. Tavares, Patrícia Portela, David Machado e Ana Margarida de Carvalho, ao lado de Ricardo Adolfo e Paulina Chiziane - autores angolano e moçambicano - , todos unidos neste projeto pela língua que compartilham e pelo olhar que enfoca o humano para além das fronteiras territoriais.

No que tange a obra Vamos comprar um poeta, o leitor é lançado numa fábula de cunho distópico, um cenário "onde cada espaço tem um patrocinador, cada passo é medido com exatidão, e até a troca dos afetos é contabilizada"4. O universo construído por Afonso Cruz proporciona, por meio da experiência de leitura, um estranhamento ou um mal-estar no leitor: aquele que desde a Revolução Francesa integra as civilizações urbanas e industriais, nesta narrativa contemporânea e inusitada, é levado às últimas consequências. Agora, o sujeito tem sua identidade esfacelada pelo sistema regido pelo cálculo, pelo lucro, pela produção em massa, pela troca de mercadorias, pela divulgação de marcas inscritas no próprio corpo do ser. Destituídos de uma subjetividade, as personagens que circulam nesta narrativa não só falam, como agem e sentem de acordo com o ideal capitalista na sua face mais predatória e cruel. Neste cenário, as qualidades sensíveis são tidas como inúteis, ao ponto de os afetos constituírem um "dividendo":

Dizem que é bom transacionarmos afetos, liga as pessoas e gera uma espécie de lucro que, não sendo um lucro de qualidade, já que não é material e não é redutível a números ou dedutível nos impostos ou gerador de renda, há quem acredite - é uma questão de fé - , que pode trazer dividendos (CRUZ, 2020, p. 7).

A quase aniquilação da subjetividade atrelada ao meio estritamente industrial no qual essas criaturas estão imersas é refletido principalmente pela linguagem utilizada na composição da narrativa. Termos como "lucro", "qualidade", "dividendo", "renda", dentre tantos que pertencem ao léxico da linguagem econômica constituem a forma linguística com que as personagens se comunicam. O materialismo radical atinge a linguagem tornando-a uma estrutura objetiva, desprovida de subjetivismo que reflete a realidade amarga e induz ao mal-estar. A relação dessas personagens com a língua dá a ilusão de que a palavra é igual a coisa nomeada e quando há a presença de uma metáfora, por exemplo, a narradora é capaz de questionar a sua composição de modo a demonstrar a estranheza perante a construção de sentido que determinada expressão sugere: 
Maçã do rosto é uma expressão esquisita e incompreensível, já que está mais do que provado que não existem maçãs no rosto, é mais do que evidente que nascem nos hipermercados ou pelo menos é lá que são recolhidas para a manutenção da saúde e da mais básica nutrição (CRUZ, 2020, p. 8).

Destituídos de uma identidade ${ }^{5}$, de um nome próprio, as personagens são referenciadas por meio da ótica da narradora-personagem que, por pistas deixadas ao longo do texto, sabemos que se trata de uma menina. Ela, por sua vez, narra a história da sua família composta pelo pai, pela mãe e pelo irmão. E, mais tarde, pela figura de um poeta. Este, também, destituído de um nome próprio, mas cuja individualidade é construída por meio de elementos que fogem à norma.

O poeta, por sua vez, consiste numa mercadoria a ser comprada. E tal desejo parte da narradora-personagem que, durante o jantar, diz: "Gostava de ter um poeta. Podemos comprar um?” (CRUZ, 2020, p. 12). Diante do desejo da filha - que, segundo o seu irmão, era uma pessoa "caprichosa e que só [se] interess[a] por coisas inúteis com pouco valor no que concerne ao crescimento económico ou com um valor de mercado desprezível (CRUZ, 2020, p.18) - o pai questiona: "por que não um artista?" e, a mãe, por sua vez, alega: "Nem pensar, fazem muita porcaria, a senhora 5638,2 tem um e despende três a quatro horas por dia a limpar a sujidade que ele faz com as tintas naqueles objetos brancos" (CRUZ, 2020, p. 12). A escolha do novo produto passa pela concepção de que os artistas "fazem muita porcaria”; já os poetas são entretidos com "cadernos com folhas brancas e canetas e a eles também será admitido adquirir alguns livros" (CRUZ, 2020, p. 16). Em resumo, as suas ações resultam das ausências de praticidade e de dividendos que poderiam gerar para a família.

Artistas, pintores, escultores e poetas constituem um produto a ser adquirido pelas famílias como se fossem uma espécie de animal de estimação ou objetos que, aparentemente, servem para o deleite desses seres enrijecidos se divertirem com a excentricidade, com o modo obtuso que suas aquisições veem o mundo, o que faz com que a arte integre esta civilização comercializada e dominada pela técnica, tornando-se um produto, uma mercadoria a ser adquirida, embora "inutilista", incapaz de gerar lucro e passível de subversão.

$\mathrm{Na}$ loja onde os poetas estão à venda, há exemplares de muitos tipos: "poetas baixos, altos, louros, com óculos (são mais caros), sendo a maior parte, sessenta e dois por cento, carecas, e sessenta e oito por cento de barba" (CRUZ, 2020, p. 14). A menina interessa-se por aquele que "era ligeiramente marreco, uma escoliose com uma curvatura oblonga" e sua descrição continua:

Trajava um colete de fazenda, setenta e cinco por cento lã, sendo os restantes vinte e cinco nylon, calças de bombazina castanhas, pantone setecentos e trinta e dois, sapatos de couro já muito usados. Fungava e tinha um livro debaixo do braço. Nenhuma das suas roupas tinha patrocínio de marcas (CRUZ, 2020, p. 14). 
Os poetas são seres quase que animalizados, pois se aproximam dos cães, e, por isso, o pai da menina ao apontar para o poeta que fungava, pergunta, como quem quer saber se o cão era feroz: "aquele exemplar era subversivo"? (CRUZ, 2020, p. 15) e o vendedor responde num discurso que beira a ironia: "Está abaixo dos dois por cento. É sempre necessário serem um pouco subversivos ou a qualidade poética baixa demasiado e não gera lucro, ninguém compra, acabam preteridos a bailarinos ou hamsters" (CRUZ, 2020, p. 15).

Walter Benjamin, em ensaio canônico a respeito da "obra de arte na era da sua reprodutibilidade técnica”, discute o caráter aurático do objeto artístico visto na sua "autenticidade", na sua "quintessência de tudo o que foi transmitido pela tradição, a partir da sua origem” (BENJAMIN, 2012, p. 182) e critica os meios de reprodutibilidade da arte que ameaçam o seu caráter autêntico. Entretanto, como bem observa Edson Rosa da Silva, embora o capitalismo e seu método de reprodução da arte tenham interferido no fazer artístico, ainda assim, é possível identificar resíduos da aura nas obras de arte: "se essa aura declina no nosso tempo, ela nunca deixa na realidade de existir. Aparentemente perdida, ela deixa resquícios, elementos mínimos, pequenos fragmentos que a mantêm viva" (SILVA, 2017, p. 6). Sendo assim, por mais que o universo distópico em que as personagens de Vamos comprar um poeta promova a perda do lugar de ação sofrida pelos artistas (no caso o poeta) na sociedade capitalista; por mais que a arte ou os artistas sejam reduzidos a meros produtos a serem comprados - e destituídos de um lucro, um traço positivo no que tange o crescimento econômico - , ainda sim, é através da autenticidade de cada representante da arte, da sua singularidade e trabalho de plasmação que o objeto artístico reluz nesse universo imerso pelas trevas do capital. Desta forma, a figura do poeta é aquela que traz em si mesma a representação da possibilidade da aura em meio a tanta reprodutibilidade técnica e na indiferença dos meios de produção para com a subjetividade do sujeito.

O poeta, a princípio, não passa de uma criatura inofensiva, já que "os estudos afirmam que os poetas vivem com pouca relação com a realidade e com quem os rodeia" (CRUZ, 2020, p. 20). A figura obtida a princípio não passaria de um "animal de estimação", de um bem sem mais valia adquirido por essas personagens. Contudo, ele promoverá no eixo familiar uma subversão partindo da sua relação com a menina, atingindo a mãe e perpassando por cada membro da família. A extravagância, a forma inquietante com que o poeta se porta diante da vida promove a perversão do mundo regido pela lógica materialista na qual estas personagens estão inseridas. Afinal, como bem cita o próprio poeta: "Embora muitas sejam as folhas, a raiz é só uma" (CRUZ, 2020, p. 26), ou seja, todos são originários do mesmo universo, do mesmo ciclo, da mesma origem fundacional.

Em Vamos comprar um poeta, Afonso Cruz compõe uma narrativa que conversa com a filosofia, a política e possui traços de ensaio crítico ${ }^{6}$. Embora a linguagem seja própria da ficção e faça uso das estruturas narra- 
tivas, o conteúdo imposto no texto traz inúmeras reflexões sobre o mundo contemporâneo, o lugar do homem na sociedade capitalista, o avanço desenfreado dos meios de produção e o questionamento do lugar da poesia no mundo. O hibridismo que caracteriza a escrita deste autor é um elemento não só evidente como fundamental na estrutura composicional do livro que busca chamar a atenção do leitor para que o seu olhar se desautomatize do quotidiano e passe a se aproximar do olhar do poeta que, ao ver uma mosca, "foi atrás dela com um bloco e a caneta" (CRUZ, 2020, p. 26) a fim de registrar o fenômeno inédito observado.

O poeta é aquele cujo olhar se desloca para fora do cotidiano experienciado pelas demais personagens. Diante de borboletas, por exemplo, ele para e admira a presença desses animais: "Quando via borboletas ficava a olhar para elas. Aconteceu duas vezes durante o trajecto" (CRUZ, 2020, p. 17) - o que para a menina torna-se uma cena que beira ao absurdo, já que não é algo "produtivo" ou que possa "gerar lucro", para usarmos termos presentes neste universo, mas que para a figura do poeta é uma questão de estar em contato com a poesia do mundo.

O excêntrico artista observa outros objetos, seres, e, inclusive, toda a família à qual pertence. É aquele que não só vê, mas, repara no seu entorno. Diante disso, é por meio do seu olhar e da construção dos seus versos ditos como uma liberdade (ainda permitida) que as mudanças vão ocorrendo mediante as metamorfoses que vão surgindo do seu contato com as demais personagens. Os versos que recita, as palavras que lhe escorrem da boca como enigmas a serem decifrados por aqueles que não conseguem compreender as metáforas, tornam-se o meio pelo qual a menina e a mãe vão sofrendo uma espécie de transformação ao longo da narrativa. Elas representam duas borboletas, duas mulheres que em seus casulos vão se alimentando da poesia, desse código aparentemente ininteligível, mas que passo a passo vão decodificando e compreendendo a força vital que vivifica o ser: a poesia, já "que um poema se pode encontrar dentro de qualquer coisa ou mesmo espalhado no chão" (CRUZ, 2020, p. 35). E a menina declara: "Aos poucos fui começando a perceber o que o poeta dizia e já não era uma algarviada, ouvi efetivamente palavras. Mas ainda passava muito tempo a tentar perceber aquelas mentiras" e o poeta de forma precisa a corrige: "metáforas" (CRUZ, 2020, p. 32). Até que chega o momento em que a menina é capaz de discorrer sobre os benefícios da poesia, embora o irmão não lhe dê ouvidos. Isso significa que o poeta possui um poder demiúrgico, capaz de transformar os seres à sua volta, incutindo-lhes o lirismo da existência.

Nesta narrativa, há um apelo, um desejo para que o leitor diante de uma civilização material e comercial submetida à técnica perceba que ainda há espaço para a poesia. E mesmo diante de uma crise, de uma possível tragédia, não se deve abandonar os poetas, nem a própria poesia. A poesia, por sua vez, transfigura o universo e faz emergir a realidade descrita com a absoluta precisão da ambiguidade. E o poeta é aquele que "sai do banho e passa a mão pelo espelho embaciado para descobrir o seu próprio rosto" (CRUZ, 2020, p. 76). 
A narrativa traz consigo a consciência da importância da Arte e da cultura no mundo. Mesmo em um universo distópico como o descrito pelas linhas ficcionais que compõem esta obra, ainda há espaço para a cultura e a Arte de maneira geral. Dentre as possibilidades existentes em relação à manifestação artística, é por meio da poesia, que, por sua vez, tem como veículo de transmissão a figura do poeta, que a cultura e a Arte resistem, persistem e subvertem os valores impostos pela lógica, pela técnica, pelo capital. Neste texto, o leitor encontra-se diante de um verdadeiro documento de cultura que não esconde a sua força e nem o poder transformador que detém, mesmo integrado a um mundo de barbárie. Ao final da narrativa, precisamente no apêndice do livro, obtemos a seguinte constatação:

Göring disse: "Quando oiço a palavra cultura, saco do revólver”. É assim que muita gente olha para a cultura. Não é mau, é sinal que é tão importante que pode ser ameaçadora, pode fazer sacar das armas. Se a arte e a literatura não tivessem importância ninguém se preocuparia em incendiar a biblioteca de Alexandria (repetidas vezes), destruir os budas de Bamiyan ou as ruínas de Palmira. Se a cultura não fosse verdadeiramente importante, Göring não sacava o revólver (CRUZ, 2020, p. 82).

A editora Dublinense proporciona aos seus leitores o contato com esta obra única, de profundo lirismo e reflexão a respeito da sociedade contemporânea e o rumo a que ela se encaminha. Pelas linhas escritas de Afonso Cruz, e com o apelo de jamais abandonarmos a Arte, a poesia e os poetas - façamos todos os dias esta oração: "Tenho milhas a percorrer antes de dormir/ E não abandonar os poetas nos parques” (CRUZ, 2020, p. 90-91).

Com o desejo de manter viva a esperança ética e humanista do autor, a aprendizagem sutil da narradora-personagem, a importância do poeta em um mundo materialista e o projeto necessário da editora Dublinense, o leitor passa a ter certeza de que "as coisas mais importantes da vida não são utilitárias: desprezamos quem faz um gesto por lucro ou benefício e não pelo gesto em si, ou por amizade ou amor" afinal, "é na inutilidade que está o altruísmo e aquilo que o ser humano considera naturalmente mais nobre" (CRUZ, 2020, p. 83).

\section{REFERÊNCIAS}

BENJAMIN, Walter. Obras escolhidas I - Magia e técnica, arte e política: Ensaios sobre literatura e história da cultura. Trad. Sergio Paulo Rouanet. 8.ed. São Paulo: Brasiliense, 2012.

CRUZ, Afonso. Vamos comprar um poeta. Porto Alegre: Dublinense, 2020.

SILVA, Edson Rosa da. O poeta conta e canta a cidade moderna. Organon. v. 32, n. 63. p.1-17, jun-dez, 2017. 


\section{NOTAS}

1 Doutorando no programa de Pós-graduação em Letras Vernáculas na Universidade Federal do Rio de Janeiro na área de Literatura Portuguesa; Mestre em Letras Vernáculas pela Universidade Federal do Rio de Janeiro com a dissertação: Entre a leitura e a escritura, a forma romanesca de Bolor, de Augusto Abelaira (2017). Membro do grupo de pesquisa: A (im)possibilidade de dar corpo ao passado na arte e na narrativa dos séculos XX e XXI, coordenado pela Profa. Dra. Ângela Beatriz de Carvalho Faria. https://orcid.org/00000003-2132-4226

2 Nota explicativa da editora presente no final do livro acompanhada do catálogo de publicações feitas até o presente momento da edição deste volume.

3 Cf. REAL, Miguel. Flores: o século XXI - a nova narrativa portuguesa. In: O romance português contemporâneo: 1950-2010. 2ºd. Lisboa: Caminho, 2012.

4 Trecho presente na contracapa do livro.

5 Há outros personagens que surgem na narrativa, cuja nomeação é feita a partir de números, como por exemplo, uma das paixões do irmão que vem a ser designada por "X89234"; há os convidados que são referidos por Convidado 1, convidado 2, etc., por fim, as criaturas são identificadas a partir de uma numeração ou de uma posição relacional e reificada.

6 Cf. o Apêndice do livro. 
Apoio:

\section{NTî̉ piरfopp}

Programa de Pós-Graduação em Letras da

Universidade Federal Fluminense (GPL/UFF)

"Apoiado pela Universidade Federal Fluminense com recursos do

Programa Auxílio Publicação - PROPPI, 2014"

Realização:

Núcleo de Estudos de Literatura Portuguesa e Africana da UFF (NEPA) 


\title{
COLABORADORES
}

\author{
Tatiana Pequeno \\ Daniel Rodrigues \\ Ana Beatriz Affonso Penna \\ Mauro Dunder \\ Veronica Prudente Costa \\ Cátia Monteiro Wankler \\ Renata Flaiban Zanete \\ Viviane Almeida \\ Catarina Martins \\ Leonel Isac Maduro Velloso \\ Jorge Vicente Valentim \\ Paulo Ricardo Kralik Angelini \\ Carlos Roberto dos Santos Menezes
}

ISSN 1984-2090
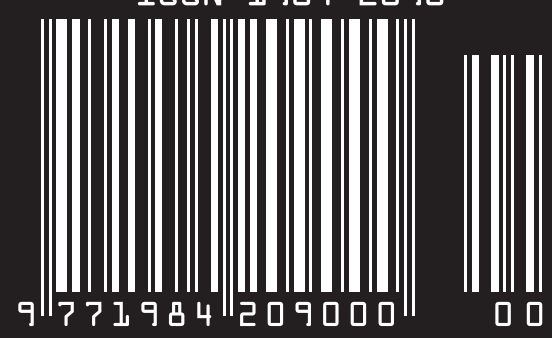